\title{
Evaluating Pool Fire Severity and the Cooling Effect of Local Water Spray Using a Continuous Plate Thermometer
}

\author{
BENJAMIN DITCH \\ FM Global \\ 1151 Boston-Providence Turnpike \\ Norwood, MA 02062 USA
}

\begin{abstract}
A methodology was developed to evaluate the maximum hazard posed to the structure of a process facility due to a large flammable liquid pool fire. The hazard evaluation was based on the vertical heat flux profile, which was measured with specially designed instrumentation based on the plate thermometer concept. Testing focused on ethanol, which produced a maximum net heat flux of $\sim 140 \mathrm{~kW} / \mathrm{m}^{2}$. The effectiveness of various water spray schemes was then evaluated on the relative reduction in the measured heat flux. Discharge densities down to $8.2 \mathrm{~mm} / \mathrm{min}$ were an effective means of reducing the fire severity to acceptable levels; however, the number and location of the discharging nozzles was shown to be critical to the system performance. For practical application beyond this project, these results were then generalized to predict the failure potential of structural members based solely on basic material properties.
\end{abstract}

KEYWORDS: flammable liquids, ethanol, reduced scale, heat flux, plate thermometer.

\section{NOMENCLATURE LISTING}

\begin{tabular}{llll}
$c_{p}$ & specific heat of gases $(\mathrm{J} / \mathrm{kg} \cdot \mathrm{K})$ & $T_{i}$ & surface temperature at time $i(\mathrm{~K})$ \\
$c_{s}$ & specific heat of object $(\mathrm{J} / \mathrm{kg} \cdot \mathrm{K})$ & $T_{o}$ & centerline plume gas temperature $(\mathrm{K})$ \\
$d$ & material thickness $(\mathrm{m})$ & $z$ & distance above fuel $(\mathrm{m})$ \\
$g$ & acceleration due to gravity $\left(\mathrm{m} / \mathrm{s}^{2}\right)$ & $z_{o}$ & virtual origin of fire $(\mathrm{m})$ \\
$t$ & time $(\mathrm{s})$ & \multicolumn{2}{l}{} \\
$\dot{q}_{\text {conv }}^{\prime \prime}$ & convective heat flux $\left(\mathrm{kW} / \mathrm{m}^{2}\right)$ & Greek & \\
$\dot{q}_{\text {loss }}^{\prime \prime}$ & heat flux loss term $\left(\mathrm{kW} / \mathrm{m}^{2}\right)$ & $\varepsilon$ & emissivity $(-)$ \\
$\dot{q}_{\text {net }}^{\prime \prime}$ & total net flux $\left(\mathrm{kW} / \mathrm{m}^{2}\right)$ & $\rho_{\infty}$ & ambient gas density $\left(\mathrm{kg} / \mathrm{m}^{3}\right)$ \\
$T_{A S T}$ & adiabatic surface temperature $(\mathrm{K})$ & $\rho_{s}$ & density of metal target $\left(\mathrm{kg} / \mathrm{m}^{3}\right)$ \\
$T_{\infty}$ & ambient temperature $(\mathrm{K})$ & $\sigma$ & Stefan-Boltzmann constant $\left(\mathrm{W} / \mathrm{m}^{2} \cdot \mathrm{K}^{4}\right)$
\end{tabular}

\section{INTRODUCTION}

Understanding the hazard posed to steel structural members from flammable liquid pool fires is an important problem in fire protection engineering. The failure potential of a steel member is primarily dependent on the material properties, the magnitude and duration of the fire exposure, and the fire protection. Considerable work has been done to predict the failure potential under a known heating condition resulting in several established numerical and empirical models [1]. These models are useful for an unprotected target structure, but become limited without a clearly defined heating condition or known effectiveness of fire protection. As a result, current protection system guidelines have largely been established through a limited number of large-scale fire tests.

With the multitude of new flammable liquids entering the commercial market each year, a methodology is needed to characterize the fire hazard and the effectiveness of the many protection system options at a reduced scale. This work focuses on the maximum fire hazard from a large ethanol pool fire, i.e., the heat flux to a fully immersed object. The subsequent protection provided by several water spray systems, commonly used to cool the lower portions of structural columns, is then quantified. To fully characterize the fire hazard, a reduced scale test was developed to produce the maximum fire hazard of a large pool fire. This was accomplished by partially enclosing the pool on two adjacent sides with non-combustible walls. The presence of the walls substantially decreased the pool size needed to achieve the maximum fire exposure. The hazard evaluation was then based on the vertical heat flux profile at the wall intersection, 
which was measured with specially designed instrumentation based on the plate thermometer concept. The fundamental knowledge of the thermal exposure to objects immersed in large pool fires will also be useful in predicting the hazard for facilities with types of construction beyond the scope of this project.

\section{SELECTION OF INSTRUMENTATION}

The primary focus of this project was to measure the flame heat flux from a large steady-state pool fire. The two most common methods to measure incident heat flux are Schmidt-Boelter (S-B) heat flux gages and plate thermometers [2,3]. Previous work conducted by the Sandia National Laboratory has shown that each of these methods exhibits similar measurement uncertainty, in the range of $24 \%$ to $40 \%$ depending on the fire environment [4]. This emphasizes the importance of selecting the proper measurement technique for the intended fire environment. For instance, S-B gages are best suited for measurements outside of the fire or for highly transient fires and are characterized by high sensitivity and a fast thermal response. However, they require internal cooling to operate properly, which is impractical for measurements inside a sooty fire where thermophoresis (i.e., soot deposition onto cold surfaces) can change the gage sensitivity. Conversely, plate thermometers are well suited for measurements inside of a fire under steady-state burning conditions [3]. They have a slower thermal response than an S-B gage, which is not critical for a steadystate fire, and can withstand the high heat fluxes present inside a fire without internal cooling. Considering this rationale, the plate thermometer technique was selected for this study.

\section{TEST SET-UP}

This evaluation consisted of a liquid pool fire that was enclosed on two sides with $8.5 \mathrm{~m}$ tall walls. The two pan sizes available were $4.4 \mathrm{~m}^{2}$ and $18.9 \mathrm{~m}^{2}$. Each enclosing wall consisted of twenty-four $1.2 \times 2.4 \mathrm{~m}$ sections of $3.2 \mathrm{~mm}$ thick sheet steel that were continuously welded on the side facing toward the fire. The sheet steel was bolted to $1.59 \mathrm{~mm}$ corrugated steel panels, which were then supported by $7.6 \mathrm{~m}$ tall steel racks. Figure 1 shows an elevation and plan view schematic of the test structure.

The enclosing walls were raised $0.3 \mathrm{~m}$ above the floor to allow the inside edge of the fuel pan, which has a $50.8 \mathrm{~mm}$ angle at the top of the pan wall, to be flush with the enclosing walls. This resulted in a total wall height of $8.8 \mathrm{~m}$ above the floor. Any gaps between the pan and enclosing walls were filled with ceramic fiber insulation.
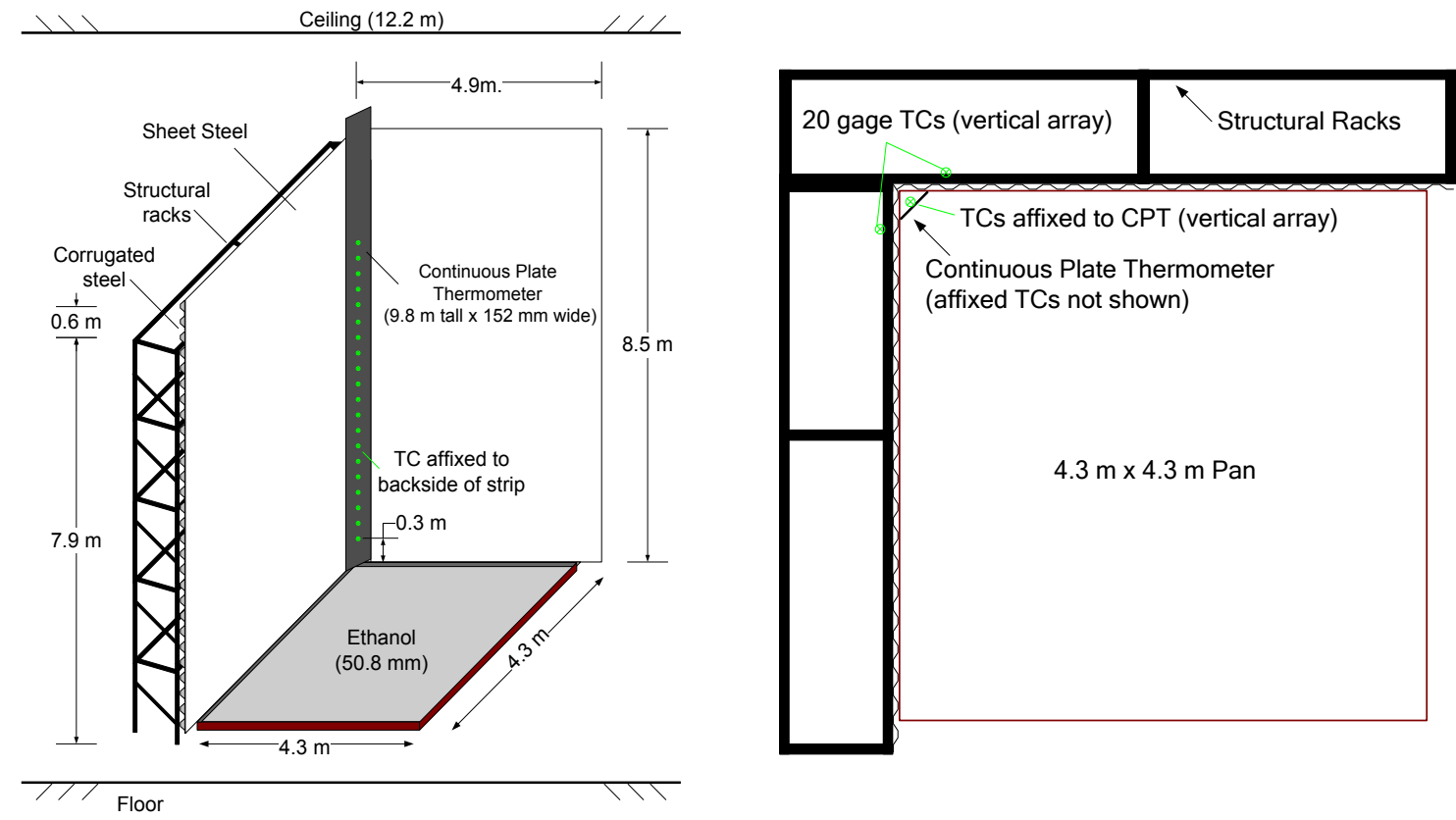

Fig. 1. Elevation and plan view schematic of test structure. 
The majority of testing was conducted using SDA-40B 200 proof ethanol. This fuel was selected specifically because the denaturant is comprised of other alcohols, which do not affect the burning characteristics. For each test, a quantity equivalent to $50.8 \mathrm{~mm}$ of fuel was poured into the pan. The resulting fuel quantities for the $4.4 \mathrm{~m}^{2}$ and $18.9 \mathrm{~m}^{2}$ pans were $231 \mathrm{~L}$ and $927 \mathrm{~L}$, respectively. This fuel depth was used to reduce dilution during the tests with suppression water.

\section{Continuous Plate Thermometer}

Measurement of the vertical profile of net heat flux was accomplished with a new application of the plate thermometer concept [3] to a tall metal channel. The resulting instrument, referred to here as the continuous plate thermometer (CPT), measures the temperature of an insulated thermocouple fastened to the backside of a thin metal plate. These measurements are then the basis for a hazard analysis of the potential for failure of metal objects subjected to similar conditions.

The actual measurement represents an integrated average of the heat flux from the flame surrounding the instrument less any conductive losses and cooling provided by applied water spray. As with all temperature measurements, consideration must be given to the local environmental conditions of the instrument, as well as, any potential loss terms. Here, the environmental conditions vary from exposure to a freeburn fire to subsequent cooling and blockage from a water sheet (of unknown thickness) by means of applied water spray. As a result, the corresponding conductive losses under these conditions also vary significantly and were not measured. This is a reasonable simplification given that the temperatures predicted to damage steel, as discussed later, are relative low.

As shown in Fig. 1, the CPT was mounted at the intersection of the two adjacent walls partially enclosing the pan. The CPT was constructed from four $2.4 \mathrm{~m}$ long $\times 0.3 \mathrm{~m}$ wide $\times 0.38 \mathrm{~mm}$ deep strips of sheet steel that were formed into $152.4 \mathrm{~mm}$ wide $\times 50.8 \mathrm{~mm}$ deep open channels, Fig. 2 . The channels were then fit end-to-end with a $7.6 \mathrm{~mm}$ overlap to result in a continuous $9.4 \mathrm{~m}$ long channel and secured together with sheet steel screws. At one-foot $(0.3 \mathrm{~m})$ increments a total of twenty $1.6 \mathrm{~mm}$ ungrounded stainless steel sheathed thermocouples were mechanically fastened to the backside of the CPT channel. The fastening mechanism was a $12.7 \mathrm{~mm}$ bolt threaded through a small metal channel that was spot welded to the backside of the CPT face, Fig. 2. The entire channel was then filled with $50.8 \mathrm{~mm}$ thick ceramic fiber insulation (having a thermal conductivity of $0.14 \mathrm{~W} / \mathrm{m} \cdot \mathrm{K}$ at $650{ }^{\circ} \mathrm{C}$ ) and sealed with $152.4 \mathrm{~mm}$ wide $\times$ $3.2 \mathrm{~mm}$ thick sheet steel. For stability, an open frame was constructed with $25.4 \mathrm{~mm}$ wide $\times 6.5 \mathrm{~mm}$ thick angle iron. The CPT was secured to the frame with wire bands located $0.3 \mathrm{~m}$ apart, with each band centered between thermocouple locations. The frame was then welded to the enclosing walls every $1 \mathrm{~m}$ with metal tabs that provided a $25.4 \mathrm{~mm}$ gap between the CPT and the walls. This gap was necessary to ensure that only suppression water aimed directly at the CPT accumulated on the measurement surface. Without the gap, water drops deflected on the enclosing walls may also have accumulated.

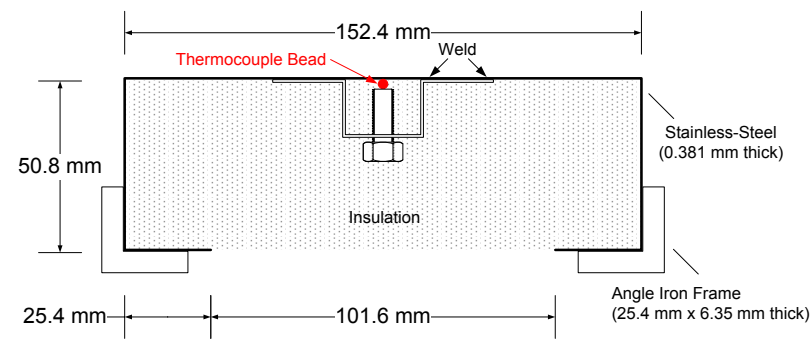

Fig. 2. Cross-sectional schematic of continuous plate thermometer.

Consistent with the measurement technique describe by Wickström [3], the total net heat to a surface at ambient temperature under steady-state heating conditions, neglecting convection, can be calculated as

$\dot{q}_{n e t}^{\prime \prime}=\sigma \varepsilon\left(T_{A S T}^{4}-T_{\infty}^{4}\right)$ 
Here, $\sigma$ is the Stefan-Boltzmann constant with the value of $5.67 \times 10^{-8} \mathrm{~W} / \mathrm{m}^{2} \cdot \mathrm{K}^{4}, T_{\infty}$ is the ambient surface temperature in $K, T_{A S T}$ is the effective black-body temperature (i.e., steady-state temperature of the CPT) in $\mathrm{K}$, and the emissivity $(\varepsilon)$ should be set to 1.0 for a black-body. The resulting value represents the maximum imposed heat flux as the emissivity of the CPT is conservatively assumed as unity.

Now, the thermal response of a thermally-thin surface exposed to an incident heat flux, $\dot{q}_{i n c}^{\prime \prime}$, can be calculated with knowledge of the material properties and the representative local flame temperature.

$T_{i+1}=T_{i}+\frac{\Delta t}{\rho_{s} c_{s} d}\left(\dot{q}_{\text {inc }}^{\prime \prime}-\dot{q}_{\text {loss }}^{\prime \prime}\right)$,

where $T_{i}$ is the surface temperature at time $i, \rho_{s}$ is the density of the surface in $\mathrm{kg} / \mathrm{m}^{3}, c_{s}$ is the specific heat of the surface in $\mathrm{J} / \mathrm{kg} \cdot \mathrm{K}, d$ is the thickness of the surface in $\mathrm{m}$, and $\dot{q}_{\text {loss }}^{\prime \prime}$ is the heat flux loss term due to conduction in $\mathrm{kW} / \mathrm{m}^{2}$. Assuming $\dot{q}_{\text {loss }}^{\prime \prime}$ can be neglected; the surface temperature can also be calculated via the adiabatic surface temperature as

$T_{i+1}=T_{i}+\frac{\Delta t\left[\varepsilon \sigma\left(T_{A S T}^{4}-T_{i}^{4}\right)\right]}{\rho_{s} c_{s} d}$.

For example, the CPT was constructed of $0.381 \mathrm{~mm}$ thick steel, having a density, $\rho_{s}$, of $7833 \mathrm{~kg} / \mathrm{m}^{3}$ and a specific heat, $c_{s}$, of $465 \mathrm{~J} / \mathrm{kg} \cdot \mathrm{K}$. Actual measurements of ethanol fire plume temperatures have not been well documented; however, studies suggest that the average temperature should be at least $800{ }^{\circ} \mathrm{C}$ to $900{ }^{\circ} \mathrm{C}$. Assuming the upper gas temperature of $T_{g}=900^{\circ} \mathrm{C}$, the measurement surface reaches the steady-state flame temperature in $\sim 30 \mathrm{~s}$. This short time duration is far below the steady-state fire durations used in this project.

\section{Water Spray Protection Schemes}

The protection systems used in these tests were representative of common industry practices for water spray protection of structural members. The two types of systems included were direct-impingement spray protection and run-down spray protection, Fig. 3. For a direct-impingement system, a uniform water density is applied to an object both horizontally and vertically. Comparatively, for a run-down system, the same total quantity of water is applied only to the top of the object and the delivered density is then averaged over the entire area of the object, i.e., the water must run down the object's surface.

Directional water spray protection was provided by a nozzle at one or more elevations above the fuel pan with a $0.76 \mathrm{~m}$ offset from the continuous plate thermometer. Each nozzle was aimed horizontally to represent a series of nozzles that surround an object. The three nozzle elevations were $1.5,3$, and $4.6 \mathrm{~m}$ above the floor. Each of the selected nozzles had a full-cone discharge pattern and a discharge angle of 90 degrees. A standoff distance of $0.76 \mathrm{~m}$ provided protection over a nominal $0.76 \mathrm{~m}$ vertical section of the CPT. Details of the four selected nozzles are shown in Table 1.

Table 1. Spray nozzle characteristics.

\begin{tabular}{|c|c|c|}
\hline K-factor & Orifice diameter & Volume median diameter $\left(d_{50}\right)$ \\
\hline$\left(\mathrm{L} / \mathrm{min} / \mathrm{bar}^{1 / 2}\right)$ & $(\mathbf{m m})$ & $(\mu \mathrm{m})$ \\
\hline 50.9 & 9.5 & 920 \\
\hline 25.5 & 7.1 & 700 \\
\hline 10.2 & 5.8 & 630 \\
\hline 17.9 & 4.8 & 450 \\
\hline
\end{tabular}




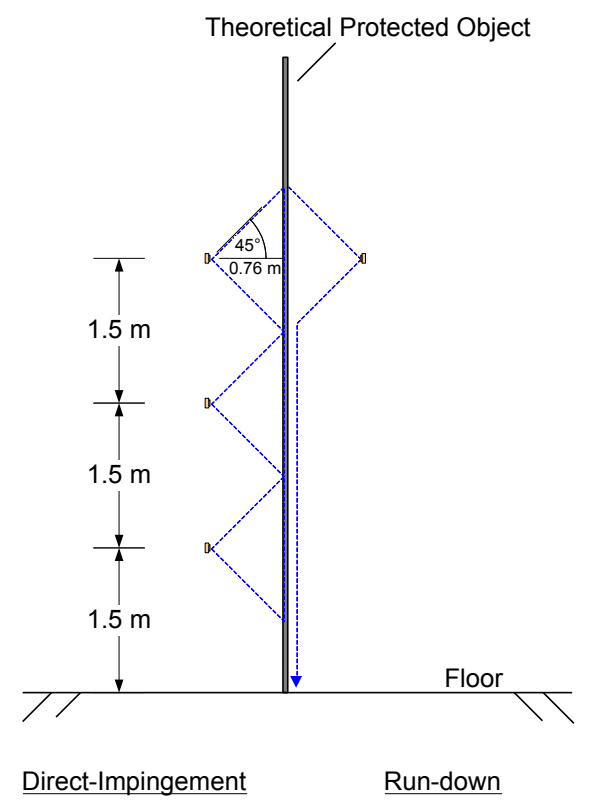

Fig. 3. Schematic of water spray protection schemes.

\section{TEST RESULTS}

An overview of test configurations and maximum heat fluxes measured is shown in Table 2. The thermal hazard to structural members from a large unprotected ethanol pool fire was established with an unprotected $18.9 \mathrm{~m}^{2}$ pan fire. An additional unprotected test with a $4.4 \mathrm{~m}^{2}$ pan was conducted to confirm the minimum dimensions necessary to achieve optically thick flames. The remaining four tests evaluated the protection provided by various directional water spray protection schemes.

Table 2. Overview of thermal exposure tests.

\begin{tabular}{|c|c|c|c|c|c|c|}
\hline $\begin{array}{l}\text { Suppression } \\
\text { type }\end{array}$ & Pan size & K-factor & $\begin{array}{l}\text { Discharge } \\
\text { density }^{\text {a }}\end{array}$ & $\begin{array}{c}\text { Discharge } \\
\text { pressure }\end{array}$ & Elevation $^{b}$ & $\begin{array}{c}\text { Maximum } \\
\text { steady- } \\
\text { state heat } \\
\text { flux }\end{array}$ \\
\hline- & $(\mathbf{m} \times \mathbf{m})$ & $\left(\mathrm{L} / \mathrm{min} / \mathrm{bar}^{1 / 2}\right)$ & $(\mathrm{mm} / \mathrm{min})^{\mathrm{c}}$ & (bar) & (m) & $\left(\mathrm{kW} / \mathrm{m}^{2}\right)$ \\
\hline \multirow{2}{*}{$\begin{array}{l}\text { Unprotected } \\
\text { (freeburn) }\end{array}$} & 4.4 & $\mathrm{n} / \mathrm{a}$ & $\mathrm{n} / \mathrm{a}$ & $\mathrm{n} / \mathrm{a}$ & $\mathrm{n} / \mathrm{a}$ & 95 \\
\hline & 18.9 & $\mathrm{n} / \mathrm{a}$ & $\mathrm{n} / \mathrm{a}$ & $\mathrm{n} / \mathrm{a}$ & $\mathrm{n} / \mathrm{a}$ & 143 \\
\hline \multirow{2}{*}{ Run-down } & \multirow{2}{*}{18.9} & 50.9 & 12.2 & 2.1 & 4.6 & 41 \\
\hline & & 25.5 & 12.2 & 2.1 & $3.0,4.6$ & 11 \\
\hline \multirow{2}{*}{$\begin{array}{l}\text { Direct- } \\
\text { impingement }\end{array}$} & \multirow{2}{*}{18.9} & 10.2 & 8.1 & 2.6 & $\begin{array}{c}1.5,3.0 \\
4.6\end{array}$ & 12 \\
\hline & & 17.9 & 12.2 & 1.9 & $\begin{array}{c}1.5,3.0 \\
4.6\end{array}$ & 13 \\
\hline
\end{tabular}

${ }^{a}$ Discharge density indicates the area averaged water flux discharged over the entire protected area

${ }^{\mathrm{b}}$ Nozzles were located $0.76 \mathrm{~m}$ from the pan corner

${ }^{\mathbf{c}}$ Typical units for fire protection applications and are equivalent to $\mathrm{L} / \mathrm{min} / \mathrm{m}^{2}$

\section{Unprotected Fires (Freeburn)}

Two unprotected pool fires were conducted to establish the baseline for the evaluation of the effectiveness of the various water protection schemes. Figure 4 presents the maximum instantaneous heat flux calculated

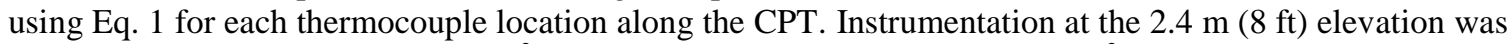
not reading properly. For the $18.9 \mathrm{~m}^{2}$ pan, a maximum heat flux of $143 \mathrm{~kW} / \mathrm{m}^{2}$ was sustained in the region of 1.8 to $4.3 \mathrm{~m}$ above the floor. As illustrated in Fig. 5, the actual flame volume in this same region changes 
substantially. Therefore, it is reasonable to conclude that the maximum flame heat flux was measured since one would expect the heat flux to decrease with decreasing flame volume if flames were not optically thick. The smaller $4.4 \mathrm{~m}^{2}$ pan produced a significantly lower maximum heat flux of $95 \mathrm{~kW} / \mathrm{m}^{2}$. Based on these results, the minimum available pan size capable of achieving optically thick flames was $18.9 \mathrm{~m}^{2}$.

The presence of optically-thick flames can be further validated based on the plume law by McCaffrey [5]. He proposes that the asymptotic plume centerline temperature occurs at $\Delta T_{o}=900 \mathrm{~K}\left(627^{\circ} \mathrm{C}\right)$ and falls off with $-5 / 3$ power of the abscissa beyond the mean flame height of the plume. This suggests that the maximum heat flux of a fire plume exists when the centerline temperature is about three times greater than the ambient temperature, i.e., $\Delta T_{o} / T_{\infty} \cong 3.0$. Rearranging the original equation, the maximum height above the pool where the maximum gas temperature exists within the plume can be predicted from

$$
\Delta T_{o}=9.1\left(\frac{T_{\infty}}{g c_{p}^{2} p_{\infty}^{2}}\right)^{1 / 3} \dot{Q}_{c}^{2 / 3}\left(z-z_{o}\right)^{-5 / 3} .
$$

Here, $T_{\infty}$ is the ambient temperature in $\mathrm{K}, g$ is the acceleration due to gravity with a value of $9.81 \mathrm{~m} / \mathrm{s}^{2}, c_{p}$ is the specific heat of air with a value of $1.0 \mathrm{~kJ} / \mathrm{kg}, \rho_{\infty}$ is the density of the air with a value of $1.2 \mathrm{~kg} / \mathrm{m}^{3}, \dot{Q}_{c}$ is the convective heat release rate in $\mathrm{kW}$, which is assumed to have a value of $0.8 \times \dot{Q}_{T}, z$ is the height above the pan in $\mathrm{m}$, and $z_{o}$ is the virtual origin of the flame.

Solving Eq. 4, it is seen that in an open air freeburn, the maximum gas temperature at the plume centerline is maintained up to $2.5 \mathrm{~m}$ above the $4.4 \mathrm{~m}^{2}$ pan and $3.8 \mathrm{~m}$ above the $18.9 \mathrm{~m}^{2}$ pan. It is important to note that, without knowledge of the flame radiation losses, the fire plume gas temperature alone is not sufficient to infer the local flame heat flux. In comparison to the experimental results, the values predicted by McCaffrey agree well for the $18.9 \mathrm{~m}^{2}$ pan, but significantly over-predict the plume temperature for the $4.4 \mathrm{~m}^{2}$ pan. This further confirms that the $18.9 \mathrm{~m}^{2}$ pan was necessary to produce optically-thick flames and the maximum fire severity.

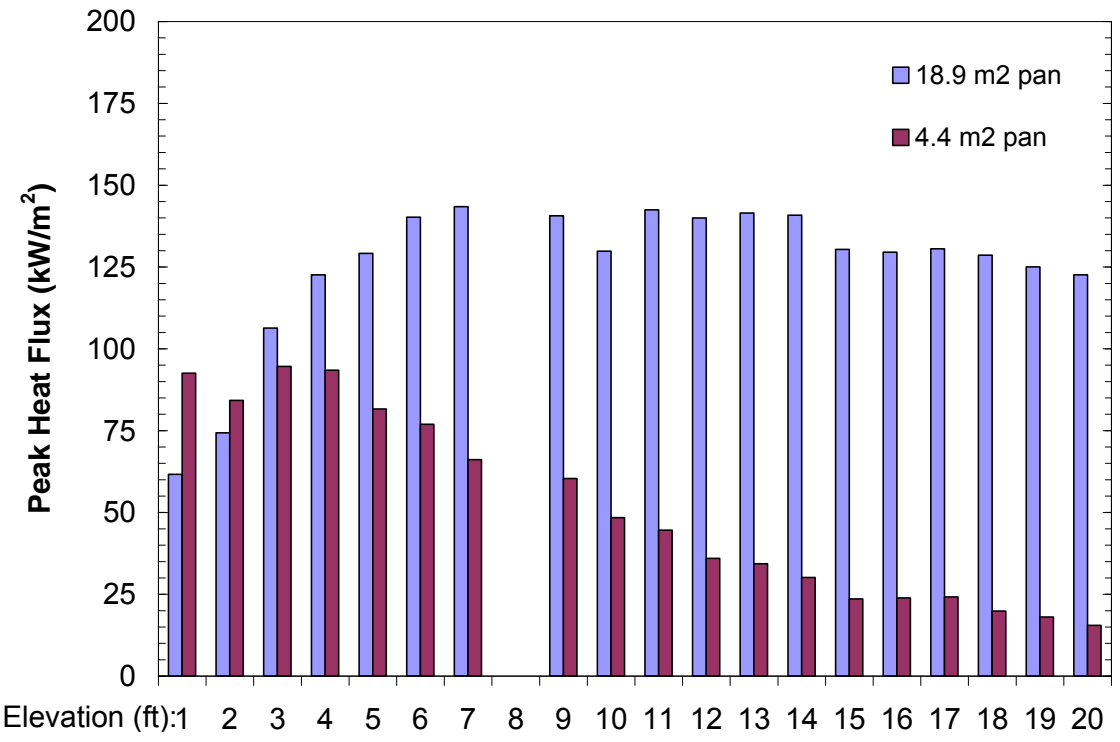

Fig. 4. Freeburn fire hazard from ethanol pool fires (measurement elevations are shown in English units to simplify figure. For conversion to metric units, $1 \mathrm{ft}=0.3048 \mathrm{~m}$ ). 


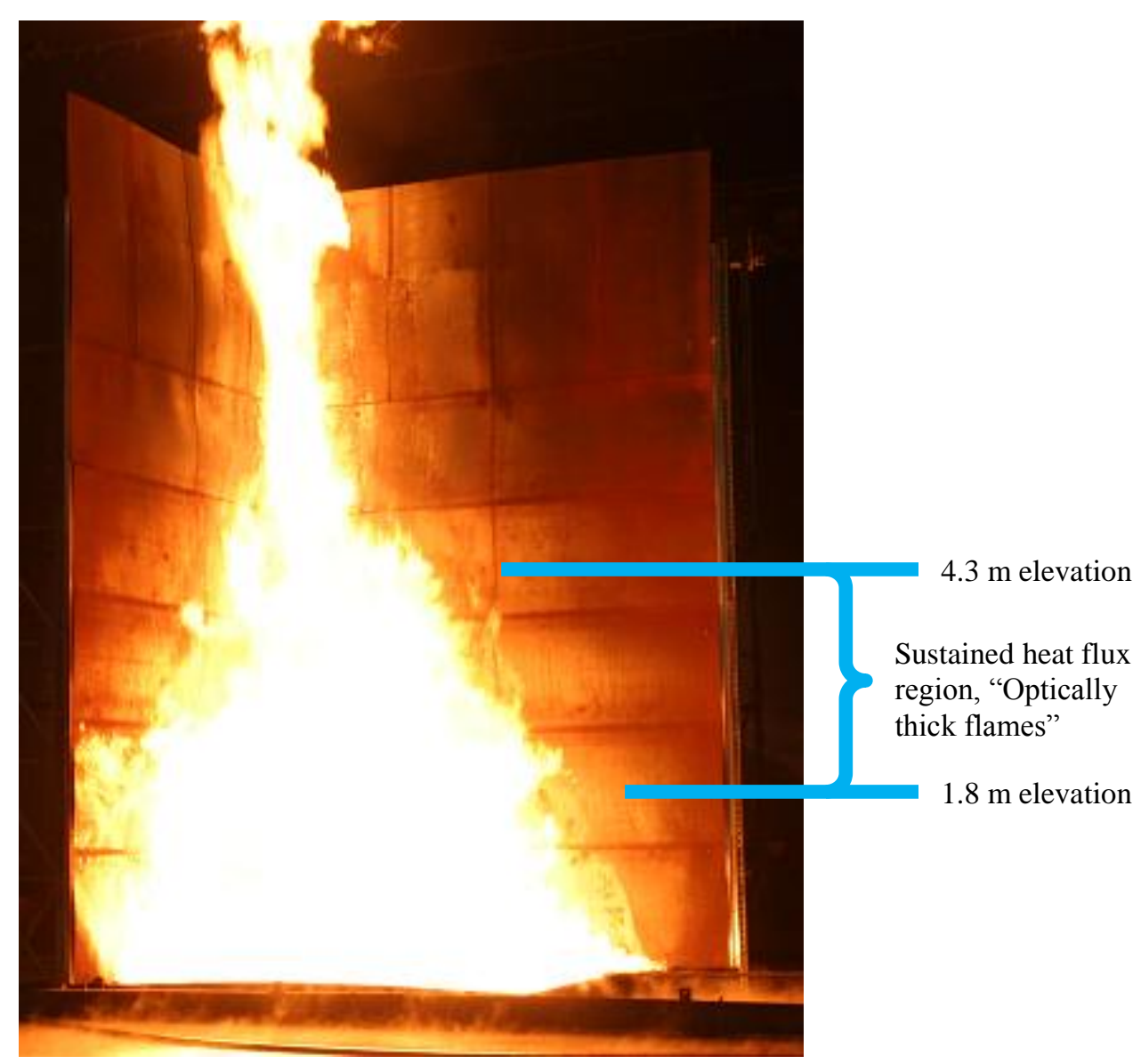

Fig. 5. Photograph of flame luminosity and volume for an $18.9 \mathrm{~m}^{2}$ ethanol fire.

\section{Direct Impingement Water Spray Tests}

Figure 6 presents the cooling provided by two direct-impingement spray protection systems compared to the maximum heat flux profile measured for the unprotected $18.9 \mathrm{~m}^{2}$ pool fire. In the first test, a discharge density of $8.1 \mathrm{~mm} / \mathrm{min}$ reduced the maximum heat flux to $12 \mathrm{~kW} / \mathrm{m}^{2}$, which was measured at $0.3 \mathrm{~m}$ above the pan. This represents a $92 \%$ reduction in the maximum heat flux compared to the unprotected fire, where it was measured $2.1 \mathrm{~m}$ above the pan. Increasing the discharge density to $12.2 \mathrm{~mm} / \mathrm{min}$, resulted in a nominally equivalent maximum heat flux of $13 \mathrm{~kW} / \mathrm{m}^{2}$, measured at $6.1 \mathrm{~m}$, or a $91 \%$ reduction compared to the unprotected fire.

These tests highlight the importance of nozzle placement on the overall effectiveness of the protection system. For instance, the area directly across from the nozzles was well protected for both discharge densities; with measured maximum heat fluxes less than $2 \mathrm{~kW} / \mathrm{m}^{2}$. The exposure increased when the flames extended above the nozzles. This was observed in both tests as an increase in the heat flux at the top two measurement locations, i.e., 5.8 and $6.1 \mathrm{~m}$. A similar increase in the heat flux occurred below the nozzles when discharging an $8.1 \mathrm{~mm} / \mathrm{min}$ density, where the maximum heat flux was measured at $0.3 \mathrm{~m}$ above the pan. Due to the geometry of the nozzle discharge, the direct spray impingement for this test only extended down to $0.8 \mathrm{~m}$ above the pan. Cooling below that point relied on collected water running down the measurement surface. For reference, though not shown, visual observation of the effect of the directimpingement water spray on the flame showed the flame volume was similar to that of the unprotected fire. 


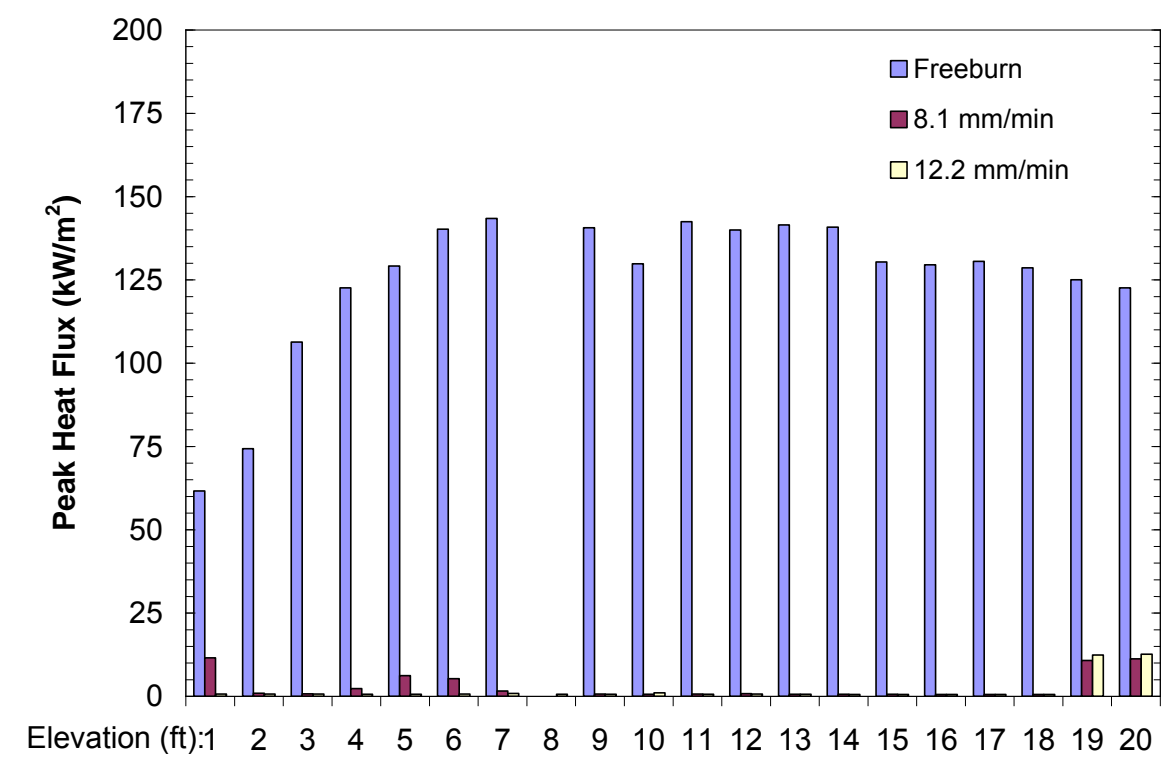

Fig. 6. Direct-impingement spray protection performance evaluation (measurement elevations are shown in English units to simplify figure. For conversion to metric units, $1 \mathrm{ft}=0.3048 \mathrm{~m}$ ).

\section{Run-Down Spray Protection}

Figure 7 presents the cooling provided by run-down spray protection compared to the maximum heat flux profile measured for the unprotected $18.9 \mathrm{~m}^{2}$ pool fire. Providing an area-averaged delivered density of $12.2 \mathrm{~mm} / \mathrm{min}$ from a single nozzle located $4.6 \mathrm{~m}$ above the floor resulted in maximum heat flux of $41 \mathrm{~kW} / \mathrm{m}^{2}$, measured $1.5 \mathrm{~m}$ above the pan. This represents a $71 \%$ reduction compared to the maximum heat flux from the unprotected fire, which was measured $2.1 \mathrm{~m}$ above the pan. Supplying an equivalent quantity of water from a spray nozzle located at 3.0 and $4.6 \mathrm{~m}$ further reduced the maximum heat flux to $11 \mathrm{~kW} / \mathrm{m}^{2}$, which was measured at $6.1 \mathrm{~m}$ above the pan, and represents a $92 \%$ reduction compared to the unprotected fire. A similar increase in the heat flux measured above and below the nozzle installation level for direct-impingement spray systems was observed for these tests. This further highlights the importance of nozzle location in the effectiveness of the protection system. Consistent with the direct-impingement tests, visual observation of the effect of the run-down water spray shows the flame volume was similar to that of the unprotected fire.

\section{Spray System Comparison}

A comparison of the cooling provided by the direct-impingement and run-down spray protection systems can also be conducted using a $12.2 \mathrm{~mm} / \mathrm{min}$ discharge density. As discussed earlier, each system discharged the same total quantity of water. The specific quantity of water discharged per nozzle was $22.3 \mathrm{~L} / \mathrm{min}$ using three nozzles, $33.3 \mathrm{~L} / \mathrm{min}$ at 3.0 and $4.6 \mathrm{~m}$ using two nozzles, and $66.2 \mathrm{~L} / \mathrm{min}$ at $4.6 \mathrm{~m}$ from a single nozzle. In each case, the heat flux measurements from 3.4 to $5.5 \mathrm{~m}$ were uniformly low. This suggests that the area of direct spray impingement was well protected for each test, regardless of the discharge volume; however, the heat fluxes tended to increase with distance from the nozzle. For these tests, a single nozzle system was not as effective as a system comprising two or more nozzles. In other words, run-down spray systems are not as effective as direct-impingement systems. 


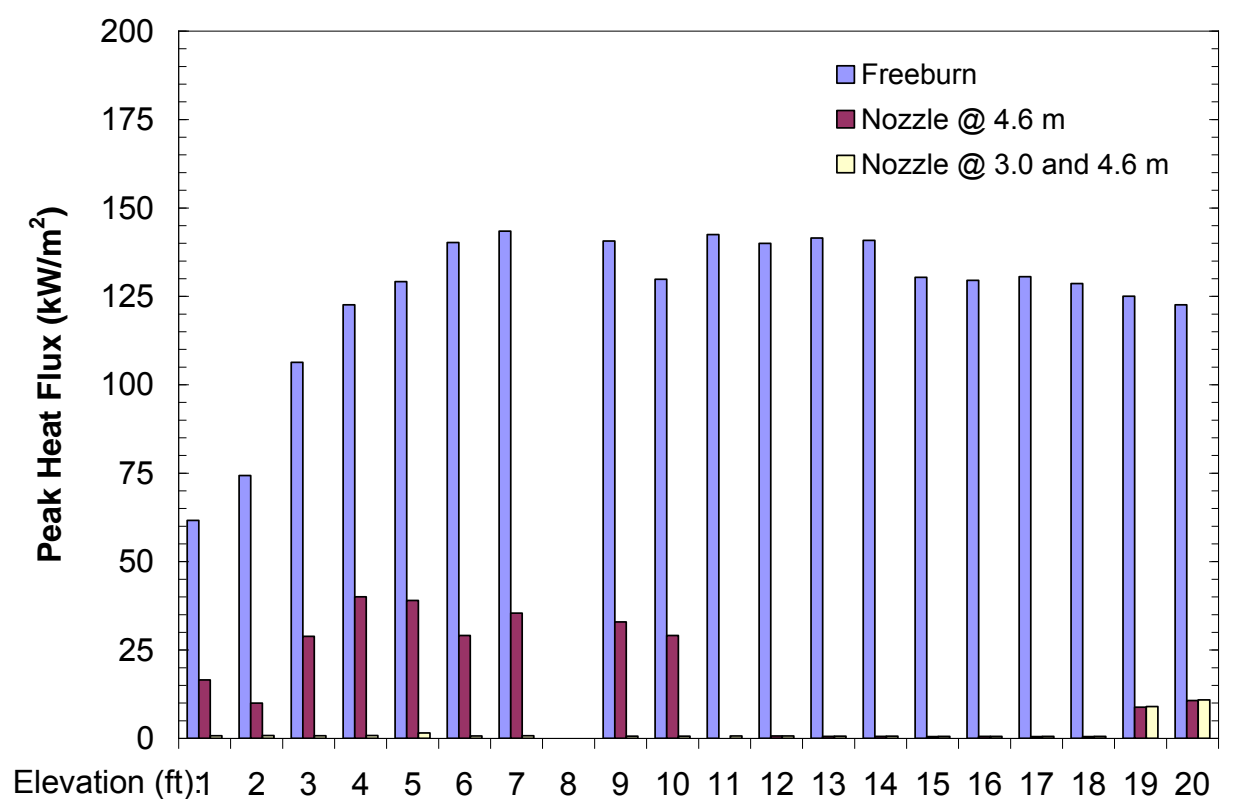

Fig. 7. Performance evaluation of run-down spray protection (measurement elevations are shown in English units to simplify figure. For conversion to metric units, $1 \mathrm{ft}=0.3048 \mathrm{~m}$ ).

\section{PREDICTION OF THERMAL DAMAGE TO STEEL MEMBERS}

The results of these tests can be generally used to predict the potential for thermal damage of structural members. For this discussion, the damage threshold will be assumed equal to the approximate softening point for steel of $538^{\circ} \mathrm{C}$. As discussed earlier, the adiabatic surface temperature for an object under steadystate radiation dominated conditions is dependent only on the incident heat flux. Therefore, the potential for failure of a structural member in each of these tests can be based solely on the maximum temperature measured with the CPT. For example, the maximum temperature measured during the baseline freeburn fire test was $981{ }^{\circ} \mathrm{C}$. This value exceeds the damage threshold value of $538{ }^{\circ} \mathrm{C}$ and indicates a strong potential for failure of objects immersed in this fire.

Figure 8 presents the maximum temperatures achieved during each of the thermal exposure tests on the primary ordinate. The heat fluxes necessary to achieve the maximum temperatures are shown on the secondary ordinate for reference and are indicated by closed circles. The tests are grouped on the abscissa based on the type of water suppression applied, i.e., direct spray impingement or freeburn scenarios. The damage threshold value of $538^{\circ} \mathrm{C}$ is included for reference.

These results indicate that the $538{ }^{\circ} \mathrm{C}$ threshold value was exceeded during all freeburn fire scenarios. The damage threshold value was also exceeded during the run-down water spray protection scenario where water was distributed from only a single nozzle. Acceptable performance was achieved during water spray protection scenarios where water was distributed from two or more nozzles.

The above results should only be used to highlight the hazard potential associated with each of the fire scenarios and suppression types included in this project. Considering the actual location of the maximum temperature achieved can provide guidance on the level of additional protection required to mitigate the hazard. 


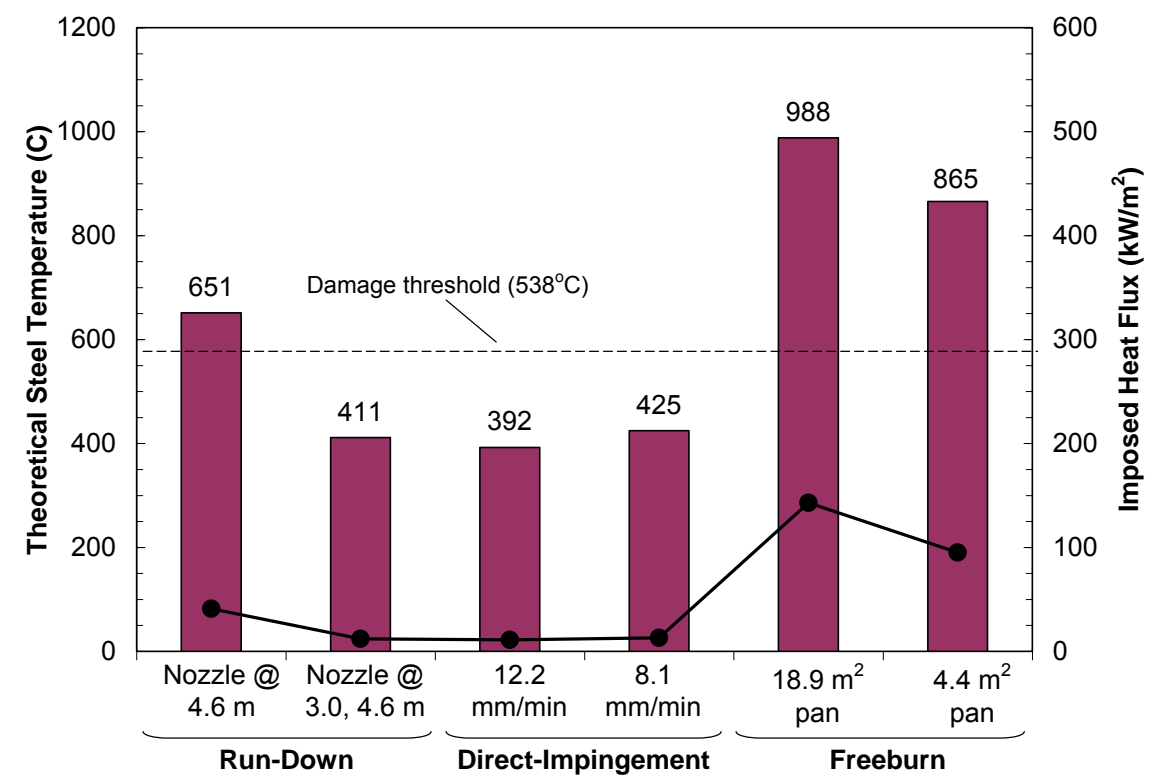

Fig. 8. Maximum surface temperature from imposed heat flux.

(Unique parameters of test set-up are shown on abscissa, i.e., nozzle location for run-down protection, discharge density for direct-impingement protection, and pan size for freeburn.)

A less conservative measure of failure potential considers the time required for an object to reach the failure threshold value, which is a function of the material properties (i.e., specific heat and density) and thickness, as shown in Eq. 3. For example, Table 3 presents the time required for representative (adiabatic) steel members to reach the damage threshold values when subjected to the heat fluxes shown in Fig. 8 . Only fire scenarios that produced temperatures in excess of the failure threshold values are included. Structural members common to a process facility are typically steel with a representative thickness ranging from 6.35 to $25.4 \mathrm{~mm}$, and material properties of $\rho_{s}=7833 \mathrm{~kg} / \mathrm{m}^{3}$ and $c_{s}=465 \mathrm{~J} / \mathrm{kg} \cdot \mathrm{K}[6]$.

In general, increasing the steel thickness from $0.35 \mathrm{~mm}$ to $25.4 \mathrm{~mm}$ resulted in an approximate $400 \%$ increase in the time required to reach either threshold value. However, even the minimum heat flux of $41 \mathrm{~kW} / \mathrm{m}^{2}$ indicated structural failure of a $25.4 \mathrm{~mm}$ thick steel member within $779 \mathrm{~s}$ (about $13 \mathrm{~min}$ ), based on the $538{ }^{\circ} \mathrm{C}$ threshold value. The maximum (net) heat flux from an ethanol fire of $143 \mathrm{~kW} / \mathrm{m}^{2}$ substantially reduced that time to $176 \mathrm{~s}$ (about $3 \mathrm{~min}$ ).

Table 3. Time to reach threshold values for two representative I-beams using the experimental maximum heat fluxes (Fig. 8).

\begin{tabular}{|l|c|c|c|c|}
\hline \multirow{2}{*}{ Test configuration } & $\begin{array}{c}\text { Pan } \\
\text { dimension }\end{array}$ & $\begin{array}{c}\text { Imposed } \\
\text { heat flux }\end{array}$ & \multicolumn{2}{|c|}{ Beam thickness } \\
\cline { 2 - 5 } & $\left(\mathbf{m}^{\mathbf{2}}\right)$ & $\left.\mathbf{k W}^{\mathbf{2}}\right)$ & $\mathbf{6 . 3 5} \mathbf{~ m m}$ & $\mathbf{2 5 . 4} \mathbf{~ m m}$ \\
\hline \hline Freeburn & 18.9 & 143 & $44 \mathrm{~s}$ & $176 \mathrm{~s}$ \\
\hline Freeburn & 4.4 & 95 & $68 \mathrm{~s}$ & $275 \mathrm{~s}$ \\
\hline $\begin{array}{l}\text { Single nozzle } \\
\mathbf{1 2 . 2} \mathbf{~ m m} / \mathbf{m i n}\end{array}$ & 18.9 & 41 & $190 \mathrm{~s}$ & $779 \mathrm{~s}$ \\
\hline
\end{tabular}

\section{CONCLUSIONS}

A methodology was developed to evaluate the fire severity posed by a large unprotected flammable liquid fire, in terms of the maximum net heat flux, and the subsequent protection provided by various water spray application schemes. The testing focused on the vertical distribution of flame heat flux as measured by a continuous plate thermometer. The overall fire size needed to maximize the fire severity was significantly reduced by partially enclosing a pool fire on two adjacent sides. The actual pan size needed is dependent on the fuel properties and will be smaller for more radiative fuels. 
In the case of ethanol, an $18.9 \mathrm{~m}^{2}$ pan was sufficient to produce the maximum net heat flux of $143 \mathrm{~kW} / \mathrm{m}^{2}$. This exposure represents a significant hazard to a process structure with potential damage to unprotected $25.4 \mathrm{~mm}$ thick steel members occurring within $3 \mathrm{~min}$. Direct-impingement water spray protection exhibited acceptable protection for uniformly applied water densities down to $8.1 \mathrm{~mm} / \mathrm{min}$. Rundown spray protection exhibited acceptable protection with an equivalent $12.2 \mathrm{~mm} / \mathrm{min}$ density when the water was applied with nozzles located 3.0 and $4.6 \mathrm{~m}$ above the pool. However, the protection became insufficient when a similar volume of water was applied with only a single nozzle located $4.6 \mathrm{~m}$ above the pool fire. For all water spray tests, the areas of direct water impingement were well protected, though the heat flux began to increase above and below the nozzle installation. This highlights the importance of nozzle location in the overall effectiveness of the protection system.

By focusing on the measurement of the vertical distribution of flame heat flux over a large pool fire, these results can be generalized to estimate the damage potential to structural columns and sensitive equipment beyond those included in this project. The importance of generalizing the results is significant given the wide range of construction practices found within any industry handling large volumes of flammable liquids.

\section{REFERENCES}

[1] Milke, J., "Analytical Methods for Determining Fire Resistance of Steel Members," The SFPE Handbook of Fire Protection Engineering ( $3^{\text {rd }}$ ed.), DiNenno P.J. (ed.), National Fire Protection Association, Quincy, MA 02269, 2002, p. 4-209 to 4-273.

[2] Janssens, M., "Fundamental Measurement Techniques," Flammability Testing of Materials Used in Construction, Transport and Mining, 2006, pp. 34 to 39.

[3] Ingason, H. and Wickström, U., "Measuring Incident Radiant Heat Flux Using the Plate Thermometer," Fire Safety Journal, 42: 161-166, http://dx.doi.org/10.1016/j.firesaf.2006.08.008

[4] Nakos, J., "Uncertainty Analysis of Steady State Incident Heat Flux Measurements in Hydrocarbon Fuel Fires," Sandia National Laboratories report SAND2005-7144, 2005.

[5] Heskestad, G., "Fire Plumes, Flame Heights, and Air Entrainment," The SFPE Handbook of Fire Protection Engineering ( $3^{\text {rd }}$ ed.), DiNenno P.J. (ed.), National Fire Protection Association, Quincy, MA 02269, 2002, pp. 2-1 to 2-17.

[6] "Thermophysical Property Data," The SFPE Handbook of Fire Protection Engineering (3rd ed.), DiNenno P.J. (ed.), National Fire Protection Association, Quincy, MA 02269, 2002, pp. A-30. 